\title{
Effect of modifiers and mineral additives from industrial waste on the quality of aerated concrete products
}

\author{
Yerlan Sabitov, iD Duman Dyussembinov*, (DDaniyar Bazarbayev \\ Department of Technology of Industrial and Civil Engineering, L.N. Gumilyov Eurasian National University, 2 \\ Satbayev str., Nur-Sultan, Kazakhstan \\ *Correspondence: dusembinov@mail.ru
}

\begin{abstract}
The given article is devoted to research of influence of polymer modifiers and mineral additives on quality of composite aerated concrete products. When selecting the composition of composite aerated concrete local raw materials and components were used: portland cement, sand, aluminum powder, polyvinyl acetate, fly ash, post-alcoholic bard and whey of milk. Preliminary polyvinyl acetate was combined with binder mixing water at a temperature above $55^{\circ} \mathrm{C}$ to obtain a readily soluble polymer emulsion. Dispersion was carried out with a rotary-pulsation apparatus at a pressure of 0.5-1.0 MPa and a rotor speed of $\sim 1200 \mathrm{rpm}$. In the same apparatus the complex modifier was produced. The offered technology of production of a complex modifier seems to be the most effective for composite aerated concrete. It made it possible to reduce water absorption and capillary suction of composite aerated concrete by an average of $25 \%$ and $45 \%$, respectively. Moreover, different combinations of fly ash, polymer and modifier made it possible to achieve optimal values of thermal conductivity, compressive strength and frost resistance of composite aerated concrete.
\end{abstract}

Keywords: composite aerated concrete, polymers, modifiers, emulsion, strength, frost resistance.

\section{Introduction}

The use of polymeric additives in cement materials can improve the whole complex of their properties: durability, tensile strength, bonding with other materials. There are two technological methods of using polymeric additives - their introduction into the composition of construction mixtures and impregnation of products [1].

For successful design of polymer-mineral compositions it is necessary to know the basic material science regulations and the dependences of physical and mechanical properties of materials on the composition, which are reflected in the theory of composite construction materials (CCM). CCMs are artificial materials of complex structures, composed of two or more monomaterials with sharply different properties, as a result of which they acquire a set of new properties that are not inherent to the original materials. From the engineering point of view, it is most important to study the overall structure of composites on two levels: the microstructure inherent in binders and the macrostructure characteristic of the composite as a whole [2].

The most effective, from the positions of more complete involvement of both cement and polymer, is the introduction of small additives of polymer into compositions at $\mathrm{P} / \mathrm{C}=0.15-0.20$ ratio. This is due to the fact that for polymer-cement systems with $\mathrm{P} / \mathrm{C}=0.2$, the most desirable structure of the inorganic binder strengthened in the defective points of the polymer binder. At higher doses of polymer hydration of cement has a limited nature, a significant part of it performs the role of microfillers, and the strength of the structure is determined mainly by the polymer component [3].

Polymers are quite widely used in products based on cement binders, in particular known additives of latexes, organosilicon compounds, fluates, polyvinyl acetate (PVA) and other polymer 
cement compositions [4]. In the technical literature, the application of polymer binder in the production of composite cellular concrete is a relatively new and insufficiently well-studied area.

This study is aimed at solving the problem of effective combination of the polymeric component of PVA with mineral binder in the manufacture of composite aerated concrete. A number of issues of interaction of water-soluble polymer and cement binder were taken into account. The work proceeded from the position that the basic materials for the preparation of composite aerated concrete should be mostly of Kazakhstan origin.

\section{Materials and methods}

The following raw materials were used in the study:

1) Natural quartz-feldspar sands from quarries in Karaganda were used as a silica component, which meets the requirements of [5]. According to chemical analysis, the sand contains alkaline oxides $\left(\mathrm{Na}_{2} \mathrm{O}, \mathrm{K}_{2} \mathrm{O}\right)$ and significant amounts of $\mathrm{Al}_{2} \mathrm{O}_{3}$, indicating the presence of feldspar minerals. At the same time, the quantitative content of $\mathrm{K}_{2} \mathrm{O}$ is slightly higher than $\mathrm{Na}_{2} \mathrm{O}$, indicating the predominance of potassium feldspar in it. The small losses during calcination indicate the insignificant presence of calcium carbonates in the sand, which is confirmed by the very minor release of carbon dioxide when the sand is exposed to hydrochloric acid. In the thermographic study of sand on the differential thermal curve, in addition to the effect of modification transformation of quartz (at $575^{\circ} \mathrm{C}$ ), a small effect associated with the release of adsorption water (at $115^{\circ} \mathrm{C}$ ) is noted. Weakly expressed endothermic effect at about $800{ }^{\circ} \mathrm{C}$ is apparently caused by dehydration of micaceous minerals and dissociation of carbonates. On the basis of data of the analysis the specified sand on structure - polymineral, and on a classification of L. Fadeev, belongs to quartz-feldspar. The sands were milled in a ball mill to a specific surface of $2500-3000 \mathrm{~cm}^{2} / \mathrm{g}$ by the device PSH-2. The content in the sand of gravel with a grain size of $5-10 \mathrm{~mm}$ is $5-15 \%$. Grain composition of the total residue on the sieve with a mesh No. 0.63 - from 30 to $45 \%$ inclusive. The content of grains with grain size less than $0.16 \mathrm{~mm}$ - not more than $15 \%$. The grain size modulus is class 2 medium and sand group 2.0 to 2.5 inclusively. The content of dust and clay particles - not more than $3 \%$. The content of clay in clumps - not more than $0,25 \%$. Bulk density when wet $-1230 \mathrm{~kg} / \mathrm{m}^{3}$. Bulk density in dry state $1355 \mathrm{~kg} / \mathrm{m}^{3}$.

2) Portland cement of Karaganda cement plant grade 400 with the following characteristics was used as a binder [6]: bulk density $-1095 \mathrm{~kg} / \mathrm{m}^{3}$; specific surface $-3150 \mathrm{~cm}^{2} / \mathrm{g}$; residue on sieve No. 008 - $8.8 \%$; normal density of cement dough - $27.1 \%$; ultimate strength at the age of 28 days 5.4 MPa. Setting time of cement were in the intervals: the beginning - from 3 hours 45 min to 3 hours $57 \mathrm{~min}$, the end - from $4 \mathrm{~h} 20 \mathrm{~min}$ to $6 \mathrm{~h} 50 \mathrm{~min}$.

3) Aluminum powder with the following characteristics: aluminum content - more than $86 \%$, hiding power in water - not less than $7000 \mathrm{~cm}^{2} / \mathrm{g}$, particle size $-35-75$ microns, gas emission rate for 4 minutes - 40-60\%, residue on the sieve No. $008-2.9 \%$.

4) Water-soluble polymer polyvinyl acetate (PVA) with the following characteristics, meeting the requirements of [7]: Mass fraction of dry residue - not less than $30 \%$; dynamic viscosity of the dispersion - 2.0-15.0 $\mathrm{mPa}$-s; $\mathrm{pH}$ level - 3.3...6.0; frost resistance - not frost-proof; deposition when diluted - not more than $1 \%$; adhesive capacity - not less than $300 \mathrm{kgf} / \mathrm{cm}$; plasticizer is present.

5) Fly ash from wastes of burnt coals in TPPs of Ekibastuz coal basin with the following characteristics, corresponding to [8]: mineralogical composition of ash - feldspar 5-10 \%, glass phase 60-65 \%, amorphized clay particles 10-15\%, corundum 5-10 \%; calcite, hydrogarnet, mullite - $3 \%$. Content of $\mathrm{SiO}_{2}+\mathrm{Al}_{2} \mathrm{O}_{3}+\mathrm{Fe}_{2} \mathrm{O}_{3}$ - about $70 \%, \mathrm{SO}_{3}$ content - 3.2-3.5\%. The ash passed the tests on uniformity of volume change. Specific surface of the tested ashes was within $2800-3000 \mathrm{~cm}^{2} / \mathrm{g}$. Chemical analysis of fly ash showed the following: humidity - 15,09\%; loss of weight on ignition $5,82 \%$; content of silicon oxide $\left(\mathrm{SiO}_{2}\right)-58,69 \%$; content of calcium oxide $(\mathrm{CaO})-3,48 \%$; content of magnesium oxide $(\mathrm{MgO})-2,42 \%$; content of sulphur trioxide $\left(\mathrm{SO}_{3}\right)-1,82 \%$.

6) Post-alcoholic bard (PAB) and whey of milk. 
To prepare PVA for the production of composite aerated concrete it is necessary to make the polymer into a readily soluble emulsion by combining it with the mixing water of the cement binder. The emulsion is required for saponification of the aluminum powder surface, which improves the contact area with the cement binder and maximize the chemical reaction. During the preparation of the emulsion, the water temperature must be at least $55^{\circ} \mathrm{C}$. This will ensure effective mixing of all components. It is also very important to consider the amount of all components in the preparation of the emulsion. The quality of the prepared emulsion can be influenced by the method of dispersion (emulsification), the temperature mode of combining in connection with which the temperature mode from $55{ }^{\circ} \mathrm{C}$ was defined. Such temperature allows together with surface-active substances (surfactants) of PVA polymer to effectively remove the paraffin layer from the surface of aluminum powder.

Rotary-pulsation apparatus (RPA) was used as a dispersant. Peculiarities of operation of RPAtype apparatuses are described in the works of A.L. Tomashpolsky and others. The main factors that cause the emulsification process in the dispersant of RPA type are pressure (0,5-1,0 MPa) and the centrifugal effect (rotor speed $\sim 1200 \mathrm{rpm}$ ). These factors cause the occurrence of high-frequency vibrations in the RPA, accompanied by cavitation and other hydrodynamic processes. This method, as practice has shown, allows obtaining high-quality emulsion. Accepted composition of polymer emulsion and scheme of its preparation are shown in Table 1 and in Figure 1.

Table 1 - Polymer emulsion composition

\begin{tabular}{cc}
\hline Components & Content, $\%$ \\
\hline Water-soluble PVA polymer & 40 \\
\hline Water & 20 \\
\hline Aluminum powder & 40 \\
\hline
\end{tabular}

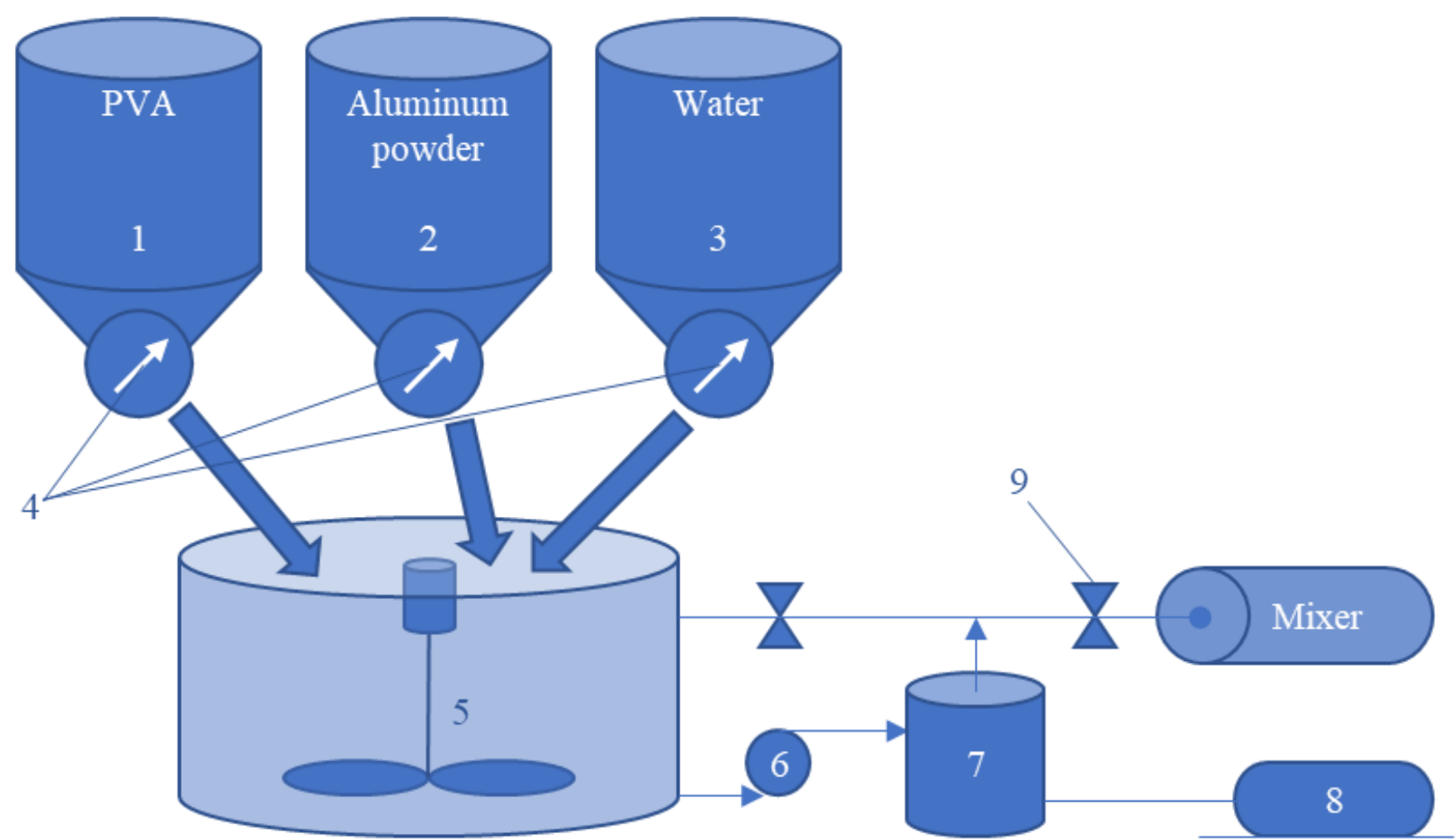

Figure 1 - Scheme of emulsion preparation: 1,3 - thermally heated PVA and water hoppers; 4 dispensers; 5 - heatable mixer; 6 - pump; 7 - RPA; 8 - electric motor; 9 - valve.

The effective emulsion was prepared according to the recommendations given in the works of V.G. Batrakov, G.I. Gorchakov, F.M. Ivanov and M.I. Higirovich.

In this case, the polymeric component of the emulsion, in addition to the role of the second binder, acts as a "saponifier" - wetting agent of aluminum powder grains, neutralizing the 
hydrophobic properties of the paraffin layer on the gas-forming grains. It is known that a fatty layer is created during the production of aluminum powder and protects it from oxidation and dusting and thus provides a synergistic effect. The experience of combining a polymer emulsion with aluminum powder is highlighted in [9] (Figure 2).

Thus, by obtaining an effective polymer emulsion with saponified and ready-to-use aluminum powder, a number of advantages are defined:

- Convenience in the production of aerated concrete products: the dusting of aluminum powder affects the health of the manufacturer's plant personnel.

- The amount of gas emitted from the chemical reaction with cement binder increases.

- The polymer component allows the aluminum powder to be evenly distributed throughout the structure of the aerated concrete mortar.

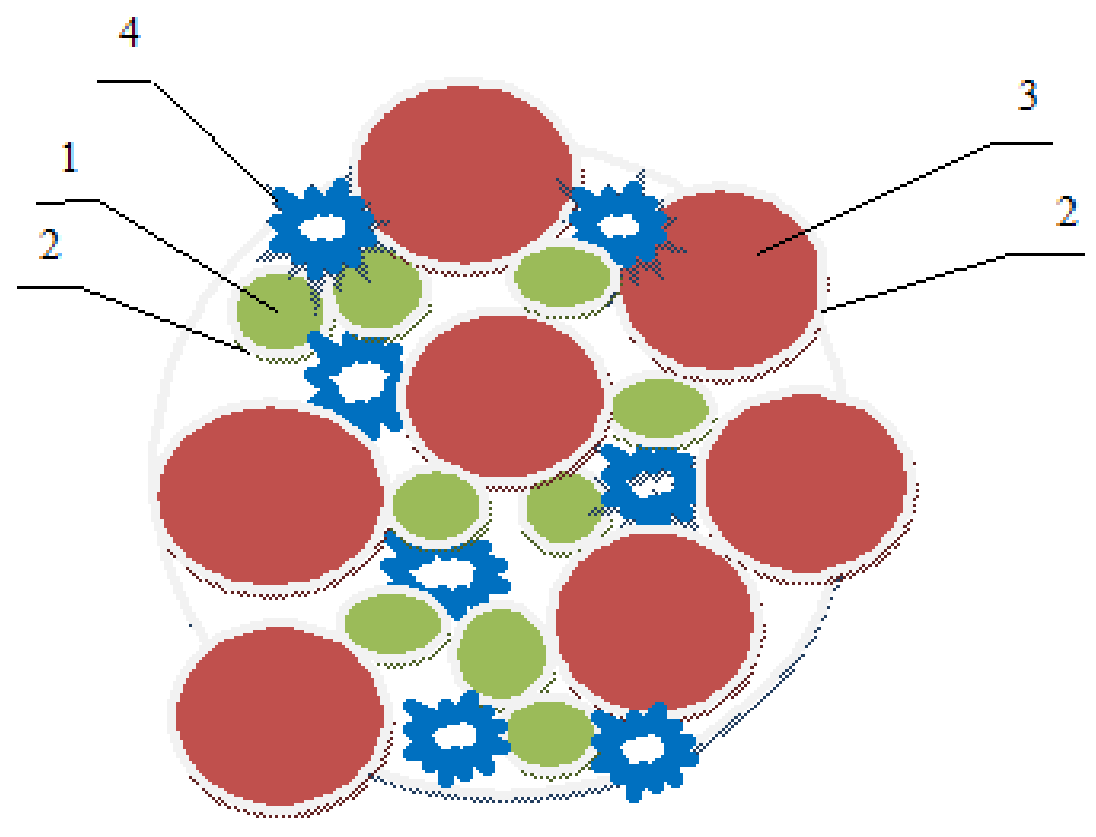

Figure 2 - Component distribution scheme of composite aerated concrete using an effective emulsion of polymer and gas-forming agent: 1 - cement binder particles; 2 - polymer binder; 3 sand; 4 - aluminum powder.

One of the disadvantages of aerated concrete products are unsatisfactory indicators of residual moisture, water absorption and capillary leakage, as well as low frost resistance. Solving these problems will fundamentally revise the performance properties of the material. In this connection, this study considers the possibilities of the complex application of hydrophilic-hydrophobic additives, which improve the physical-mechanical and chemical properties of composite aerated concrete. Reduced water absorption of composite aerated concrete cannot be ensured by increasing the dosage of polymer emulsion. However, if we consider the possibility of using complex modifiers from industrial wastes, it is quite possible to significantly increase the quality indicators within a manageable framework.

Secondary raw materials and industrial wastes were considered as components for the complex modifier. The main plasticizing component used in the study is post-alcoholic bard (PAB), hydrophobic component is whey of milk, tracer is fly ash of dry selection. The complex application of the above-mentioned components makes it possible to significantly increase the qualitative indicators of the composite aerated concrete. Figure 3 considers the method of preparation of a complex modifier, the main feature of which is the synergistic effect. When combining all components in RPA, a dispersed emulsion is obtained, which enhances the existing characteristics of all components. When combining fly ash with plasticizing components its water absorption is reduced, which positively affects the strength of the composite aerated concrete. And the use of the 
whey of milk in combination with the fly ash stabilizes its hydrogen index, bringing it closer to the neutral environment.

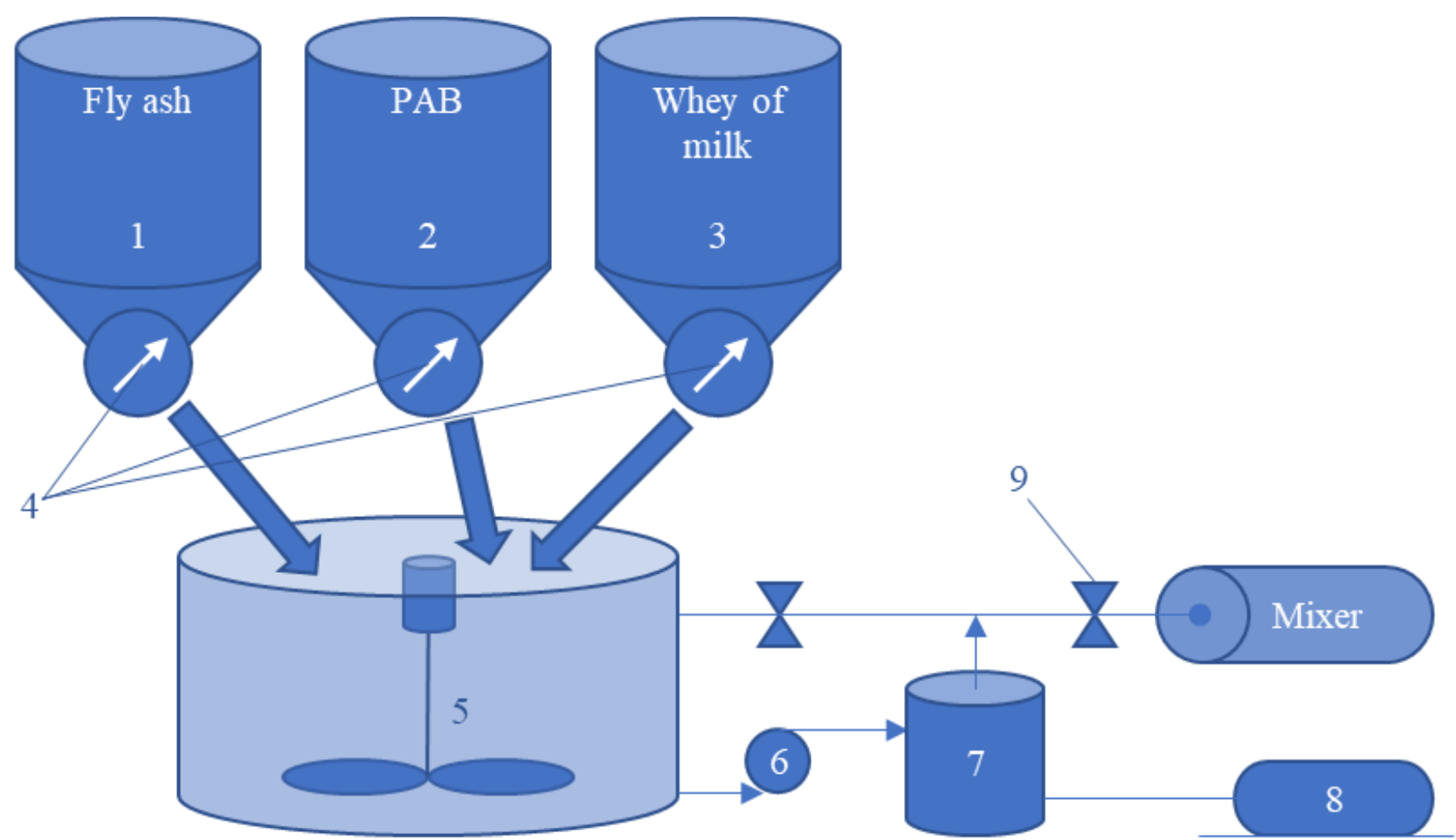

Figure 3 -Scheme of preparation of complex modifier: 4 - dispensers; 5 - mixer; 6 - pump; 7 RPA; 8 - electric motor; 9 - valve.

The accepted composition of the dispersed emulsion of complex modifier is shown in Table 2 below.

Table 2 - Disperse emulsion composition

\begin{tabular}{cc}
\hline Components & Content, $\%$ \\
\hline PAB & 35 \\
\hline Fly ash of dry selection & 30 \\
\hline Whey of milk & 35 \\
\hline
\end{tabular}

Thus, the proposed production technology of complex modifier seems to be the most effective for composite aerated concrete. The porosity of aerated concrete determines its sorptive moisture capacity and deformability, as well as largely determines the durability of aerated concrete during operation. The operating properties of cellular concrete largely depend on the structural characteristics of the material (integral and differential porosity) and the pore space geometry features. To indirectly assess the durability of cellular concrete, as well as other masonry materials, are used various indicators of their physical structure, such as density, water absorption and degree of pore filling with water, the rate of capillary suction. A characteristic that reflects the ability of moisture to migrate in the pore space of cellular concrete is capillary absorption. The capillary absorption of water by modified aerated concrete and aerated concrete without additives was determined by the well-known method, and the results are presented below.

\section{Results and Discussion}

The test results of aerated concrete for water absorption and capillary leakage are shown in Figure 4 below. 

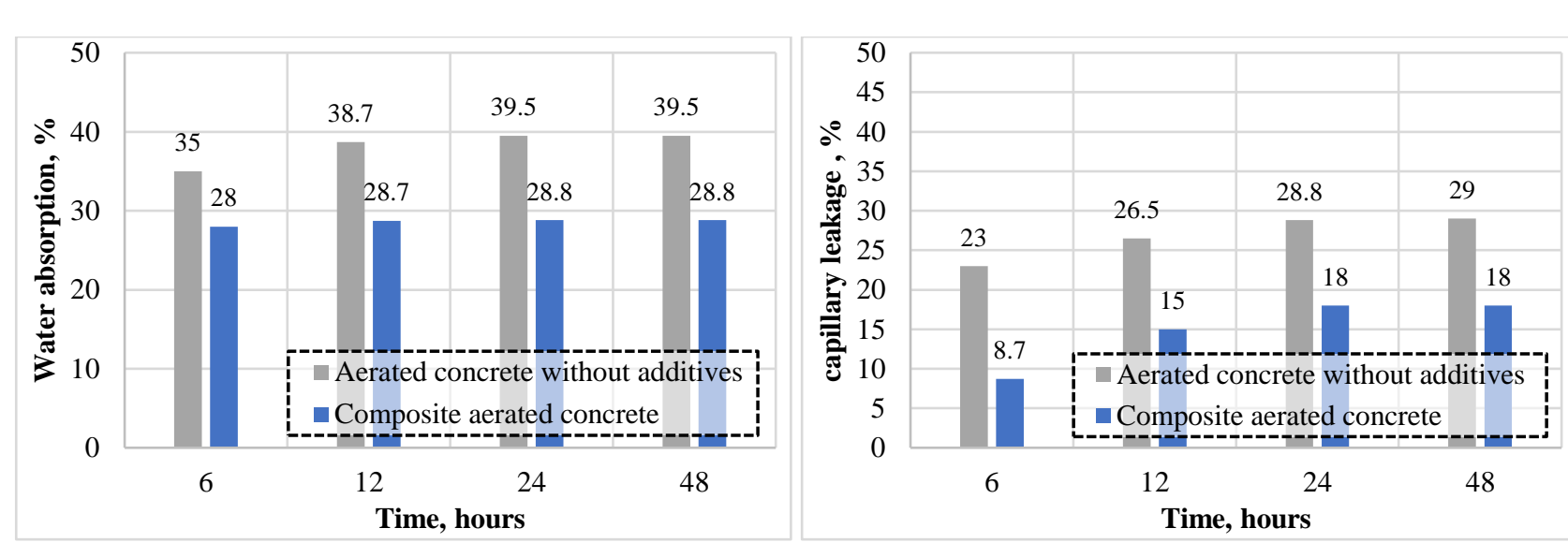

Figure 4 - Kinetics of water absorption and capillary leakage in gas concrete with an average density of $600 \mathrm{~kg} / \mathrm{m}^{3}$

The experimental results show that the composite aerated concrete has improved characteristics of water absorption and capillary leakage: water absorption and capillary leakage of composite aerated concrete are on average $25 \%$ and $45 \%$ lower, respectively. This is explained not only by the hydrophobic properties of the polymer component and complex modifiers in the aerated concrete, but also by the formation of relatively closed pores in it for the most part and the smaller diameter of capillary pores. Information about the positive effect of relatively closed pores on the hydrophysical properties of cellular concrete are given in the works of A.R. Akhmetov [10]. The work showed that the capillary absorption of water under vacuum was less in aerated concrete, the differential porosity of which was in the range from 1.5 to 300 microns. Thus, the study of water absorption and capillary suction confirmed the results obtained by A.R. Akhmetov about the low permeability of cement stone with pores smaller than 300 microns. Hydrophobization further reduces water absorption and capillary absorption of water by aerated concrete. The carried out comparative analysis allows to draw a conclusion about the best hydrophysical properties of modified aerated concrete, which during the operation of buildings constructed of these materials provide high thermal comfort indoors.

It is known that during the operation of buildings, especially in winter, in an environment with high humidity, when the insulation is located on the outer side of the wall there is a gradual accumulation of moisture, which does not have time to air out. As a result, the thermal conductivity of the insulation increases and the heat transfer resistance of the wall envelope decreases. Therefore, when operating buildings in an environment with high humidity in the winter, insulation in terms of technology is more effective to place it indoors.

Studies showed that the composite aerated concrete on ash has a reduced thermal conductivity. The results of the research are presented in Table 3.

Table 3 - Thermal conductivity of aerated concrete with different aggregates

\begin{tabular}{ccccc}
\hline Type of aerated concrete & $\begin{array}{c}\text { Grade of concrete by } \\
\text { average density }\end{array}$ & on sand & Thermal conductivity coefficient, W/m-K \\
\cline { 2 - 5 } & 600 & 0,14 & 0,12 & on ash \\
\cline { 2 - 5 } Structural and thermal & 0,17 & 0,15 & 0,12 \\
\cline { 2 - 5 } insulation & 700 & 0,22 & 0,17 & 0,15 \\
\cline { 2 - 5 } & 800 & 0,24 & 0,20 & 0,18 \\
\hline
\end{tabular}

The introduction of ash into aerated concrete leads to a decrease in its strength, which negatively affects the quality of structural and thermal insulation and structural aerated concrete products. Studies on the effect of complex modifiers on the construction and technical properties of composite aerated concrete have been conducted. Complex modifier contains fly ash of dry selection as a finely dispersed filler. We made in the standard forms and drilled composite aerated concrete specimens with complex modifiers and without additives. The obtained results of the compression 
test are shown in Figure 5 (left). Also tests on frost resistance of similar samples results of researches are shown in Figure 5 (right).
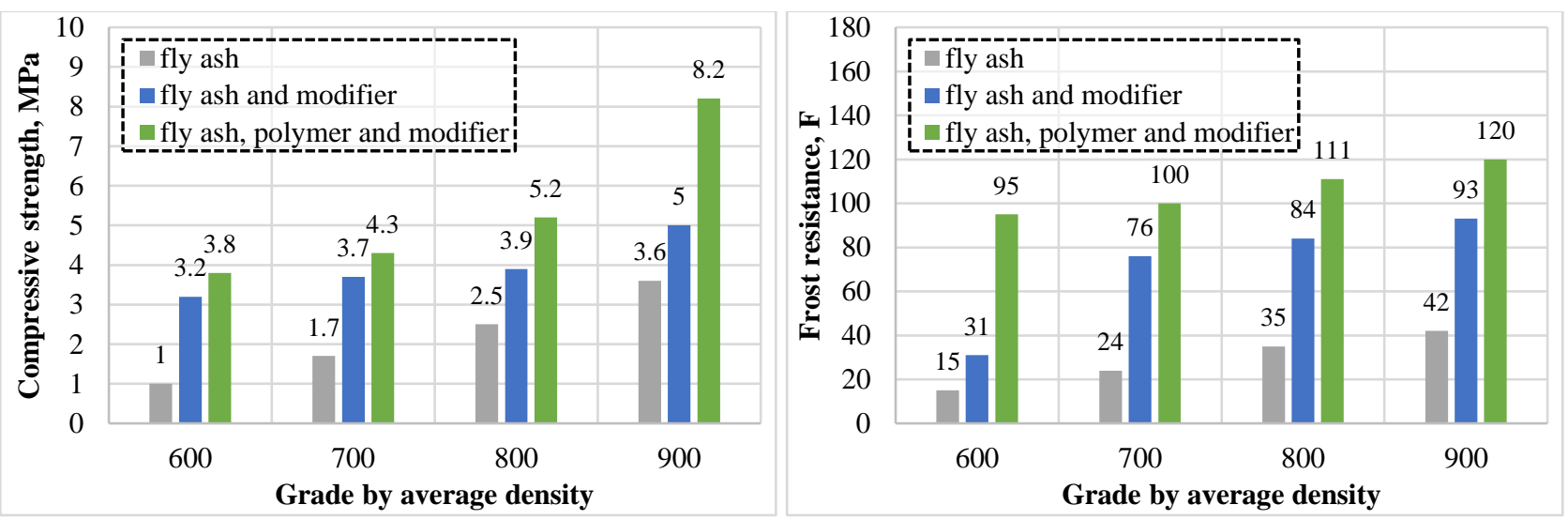

Figure 5 - Influence of polymer and complex modifier on strength and frost resistance of composite aerated concrete

The results show that the strength and frost resistance of composite aerated concrete with additives significantly increases. The best results were obtained for composite aerated concrete with a complex modifier and a polymer component. The studies showed that the specimens of aerated concrete with complex modifier even with low strength, when interacting with water, do not collapse, which indicates the effectiveness of the application of this modifier. The post-alcohol bard, which is a part of the complex modifier, contains casein, which during interaction with the filler and fine aggregate of composite aerated concrete polymerizes, forming additional contact layers that increase the resistance of the material to water.

\section{Conclusions}

The following conclusions can be made based on the results of the studies:

1. Thus, from the conducted studies it is clear that the use of complex modifiers of hydrophilichydrophobic type, a polymeric component to obtain a durable and effective material is effective when using fly ash.

2. Complex modifier from industrial wastes improves building-technical properties providing reduction of water-cement ratio and thus increasing product strength, creating a high-quality pore structure, which allows to save cement binder and solve the problem of utilization of fly ash wastes.

3. Studies have shown that the use of all elements and new developments in the production of composite aerated concrete with the selection of optimal quantities and modes will allow to obtain high-quality materials.

\section{Acknowledgments}

This research was funded by the Science Committee of the Ministry of Education and Science of the Republic of Kazakhstan (Grant № AP05132631).

\section{References}

1. Complex application of ash of hydraulic removal and modified additives such as CMA, CM-2 in the production of non-autoclaved foam concrete / D.S. Dusembinov, R.E. Lukpanov, D.V. Tsygulyov, S.B. Yenkebayev // Journal of Physics: Conference Series. — 2021. — Vol. 1926, No. 1. — P. 012041. https://doi.org/10.1088/1742$6596 / 1926 / 1 / 012041$

2. The Theory of Composites / G.W. MiltonCambridge University Press, 2002. https://doi.org/10.1017/CBO9780511613357 
3. EFFECT OF POLYMER/CEMENT RATIO AND CURING REGIME ON POLYMER MODIFIED MORTAR PROPERTIES / D. Hatungimana, Ş. Yazıc1, A. Mardani-Aghabaglou // Journal of Green Building. — 2020. — Vol. 15, No. 3. - P. 177-193. https://doi.org/10.3992/igb.15.3.177

4. Performance of Polymer Modified Mortar with Different Dosage of Polymeric Modifier / S. Ganesan, M.A. Othuman Mydin, N.Md. Sani, A.I. Che Ani // MATEC Web of Conferences. — 2014. — Vol. 15. — P. 01039. https://doi.org/10.1051/matecconf/20141501039

5. GOST 8735. Sand for construction work. Testing methods - 2018.

6. GOST 10178-85. Portland cement and portland blastfurnace slag cement. Specifications - 2004.

7. GOST 18992-80. Polyvinylacetate homopolymeric coarse breakup dispersion. Specifications - 2001 .

8. GOST 25818. Thermal plant fly-ashes for concretes. Specifications - 2017.

9. Application of Acrylate Latex Emulsion as the Binder for Coating Aluminum Substrate by Silica-Gel Powder / Y.G. Dehnavi, M. Gholami // International Journal of Air-Conditioning and Refrigeration. — 2019. — Vol. 27 , No. 04. - P. 1950032. https://doi.org/10.1142/S2010132519500329

10. FROST RESISTANCE OF COMPOSITE GAS CONCRETE / E.E. Sabitov, D.S. Dyusembinov, D.O. Bazarbaev // Vestnik Tomskogo gosudarstvennogo arkhitekturno-stroitel'nogo universiteta. JOURNAL of Construction and Architecture. - 2018. - No. 2. - P. 157-162. https://doi.org/10.31675/1607-1859-2018-20-2-157-162

\section{Information about authors:}

Yerlan Sabitov - Candidate of Technical Sciences, Head of the Department of Technology of Industrial and Civil Engineering, L.N. Gumilyov Eurasian National University, 2 Satbayev str., NurSultan, Kazakhstan, sabitov_yeye@enu.kz

Duman Dyussembinov - Candidate of Technical Sciences, Associate Professor at the Department of Technology of Industrial and Civil Engineering, L.N. Gumilyov Eurasian National University, 2 Satbayev str., Nur-Sultan, Kazakhstan, dusembinov@ mail.ru

Daniyar Bazarbayev - PhD, Associate Professor at the Department of Technology of Industrial and Civil Engineering, L.N. Gumilyov Eurasian National University, 2 Satbayev str., Nur-Sultan, Kazakhstan, phdd84@mail.ru 